\title{
A questão da tradução em versões brasileiras de canções anglófonas
}

\section{The issue of translation in Brazilian versions of English-language songs}

Lucas Martins Gama Khalil*

\begin{abstract}
Brazilian adaptation of English-language songs is a very common phenomenon, taking into account the dynamic circulation of cultural products in contemporaneity. When music artists produce these "versions", they base the songs on melodic structures that already exist and create new lyrics, in Portuguese. In most of the cases, these new lyrics do not intend to reach "fidelity" with respect to the lyrics of English-language songs. Essa noite foi maravilhosa, by Leandro e Leonardo, based on Wonderful Tonight, by Eric Clapton, has some characteristics that raise issues related to the tension between adaptation and translation, since it maintains a similar narrative. Based on theoretical reflections by authors like Hutcheon and Selligman-Silva, the study aims to analyze this musical version, especially investigating the resignifications in relation to the English-language song.
\end{abstract}

Keywords: Adaptation; translation; music; discourse.

Resumo: A adaptação brasileira de canções anglófonas é um fenômeno bastante comum, em vista da rapidez com a qual os produtos culturais circulam na contemporaneidade. Artistas musicais, quando produzem tais "versões", baseiam-se em uma estrutura melódica já existente e criam uma nova letra, em português. $\mathrm{Na}$ maioria das vezes, essas novas letras não pretendem alcançar "fidelidade" com relação às letras das canções anglófonas. Essa noite foi maravilhosa, de Leandro e Leonardo, baseada em Wonderful Tonight, de Eric Clapton, possui algumas características que suscitam questões relativas à tensão entre tradução e adaptação,

\footnotetext{
Mestrando em Estudos Linguísticos na Universidade Federal de Uberlândia. E-mail: lucas_mgk@hotmail.com
} 
tendo em vista a manutenção de uma narrativa semelhante. Baseado em reflexões teóricas de autores como Hutcheon e Selligman-Silva, o presente estudo objetiva analisar essa versão musical, investigando, sobretudo, as ressignificações em relação à canção anglófona.

Palavras-chave: Adaptação; tradução; música; discurso. 
KHALIL, L. - A questão da tradução em versões brasileiras de canções anglófonas

\section{Introdução}

As adaptações brasileiras de canções anglófonas são bastante comuns nos dias atuais, haja vista a facilidade com que canções podem ser alteradas por meio de novas tecnologias, como softwares de computador. Os efeitos de sentido decorrentes dessas produções culturais constituem o assunto principal da pesquisa de mestrado que desenvolvemos. Em tal pesquisa, empreendemos a análise de nove versões e de suas nove respectivas canções-base (isto é, canções que servem de base melódica à produção das versões), objetivando refletir sobre o modo como as materialidades das canções produzem sentidos diversos, de acordo com os públicos que as "avaliam", tanto estilisticamente quanto qualitativamente.

Essa noite foi maravilhosa, de Leandro e Leonardo, baseada em Wonderful Tonight, de Eric Clapton, é apenas uma das canções que constituem o corpus de nossa pesquisa. Neste artigo, escolhemos efetuar tal recorte pelo fato de a narrativa desenvolvida pela versão em questão assemelhar-se, em vários momentos, da que é desenvolvida na canção-base, suscitando questionamentos sobre a fronteira entre adaptação e tradução. Embora estejamos lidando com letras de música, as duas canções citadas aproximam-se de uma estrutura narrativa.

A principal problemática da pesquisa que desenvolvemos, de modo geral, diz respeito a uma regular atribuição estilística e qualitativa. Enquanto as canções-base selecionadas para o corpus são comumente associadas ao rock, as versões (cantadas com letras em português) associam-se a estilos que se relacionam, em diversos graus, à noção de "brega", tais como o "tecnobrega" e o "sertanejo". Questionamos o porquê dessa diferenciação, tendo em vista a manutenção de uma mesma estrutura melódica. Como hipótese, defendemos que essa atribuição qualitativa e estilística está mais ligada a uma construção da imagem do artista, exterior às próprias canções, do que a caracteres estritamente intrínsecos, como a qualidade artística das 
letras ou a execução da melodia. Em outras palavras, a associação de Leandro e Leonardo ao estilo "sertanejo" deve-se à estabilização de uma postura préconstruída relativa àquilo que se concebe como "artista sertanejo", representação concretizada em materialidades linguísticas e simbólicas que constituem os entornos das canções, como as capas de álbuns, para citarmos um exemplo.

Em nossa pesquisa, investigamos os diversos fatores que constituem os efeitos de sentido na produção, circulação e recepção de versões brasileiras de canções anglófonas. Dessa forma, a discussão sobre as noções de tradução e adaptação, conceitos recorrentemente suscitados na análise de versões nacionais de canções anglófonas, constitui um dos aspectos relevantes para o desenvolvimento de nossas análises.

No próximo tópico, apresentaremos algumas perspectivas teóricas sobre tradução e adaptação, objetivando refletir sobre as consequências de suas aplicações para os sentidos de um produto cultural. No terceiro tópico deste artigo, por fim, empreenderemos uma análise sobre a canção Essa noite foi maravilhosa, de Leandro e Leonardo, baseada em Wonderful Tonight, de Eric Clapton, com o intuito de identificar semelhanças, distanciamentos e ressignificações a partir da comparação entre as duas letras.

\section{Tradução, adaptação e sentido}

Ao lidarmos com versões brasileiras de canções anglófonas, recorremos constantemente a termos como "adaptação" e "tradução", tendo em vista os processos de mudança da estrutura literomusical e, sobretudo, de mudança do idioma. Entendemos que uma reflexão sobre as implicações linguísticas e discursivas concernentes à produção das versões é fundamental para uma compreensão mais acurada do fenômeno. 
KHALIL, L. - A questão da tradução em versões brasileiras de canções anglófonas

Muitas das letras das canções que denominamos "versões" afastam-se de certa concepção de "tradução". Na maioria das vezes, algumas temáticas gerais permanecem, como a temática amorosa; no entanto, elas são desenvolvidas textualmente de formas bastante diversas, de modo que não percebemos, na maioria dos casos, uma busca por "fidelidade" em relação à canção-base. Entretanto, a canção que analisaremos neste artigo, Essa noite foi maravilhosa, de Leandro e Leonardo, baseada em Wonderful Tonight, de Eric Clapton, contém alguns momentos de aproximação com uma "tradução expressão por expressão", o que nos leva a crer que o processo de produção da letra da versão considerou, em parte, a letra da canção-base.

Não estamos concebendo tal ideia de fidelidade como uma integral equivalência linguística; por outro lado, há versões, como $O$ navio e o mar, da banda Calcinha Preta, baseada em Send me an angel, da banda Scorpions, que desenvolvem temáticas significativamente diferentes em relação à cançãobase. No caso do exemplo citado, a versão tematiza a solidão, decorrente de uma relação amorosa, enquanto a canção anglófona discorre sobre a chegada de um anjo à "terra da estrela da manhã", em possível referência a Lúcifer. Portanto, quando nos referimos à "busca por fidelidade" na canção Essa noite foi maravilhosa, não consideramos uma transposição completa de sentidos, mas a produção de uma narrativa relativamente semelhante.

Segundo ARROJo (2003, p. 23):

O texto, como o signo, deixa de ser a representação "fiel" de um objeto estável que possa existir fora do labirinto infinito da linguagem e passa a ser uma máquina de significados em potencial. A imagem exemplar do texto "original" deixa de ser, portanto, a de uma sequência de vagões que contêm uma carga determinável e totalmente resgatável. Ao invés de considerarmos o texto, ou o signo, como um receptáculo em que algum "conteúdo" possa ser depositado ou mantido sob controle, proponho que sua imagem exemplar passe a ser a de um palimpsesto.

Nessa perspectiva, a suposta busca por fidelidade, mais evidente em Essa noite foi maravilhosa do que em versões como a citada $O$ navio e o mar, 
KHALIL, L. - A questão da tradução em versões brasileiras de canções anglófonas

não confere ao texto adaptado a representação exata do texto original. A versão musical brasileira é, assim como um palimpsesto, um texto cujas rasuras e singularidades constantemente deslocam as relações com a "primeira" escrita. Embora aspectos narrativos aproximem Essa noite foi maravilhosa e Wonderful Tonight, a ideia de "fidelidade" permanece no domínio de uma possível busca, pois "a tradução seria teórica e praticamente impossível se esperássemos dela uma transferência de significados estáveis" (ARROJo, 2003, p. 42).

Para problematizarmos a questão das fronteiras entre línguas na singular produção de sentidos, partimos de um questionamento feito por FOUCAULT (2000: 116): "Uma frase fielmente traduzida para uma língua estrangeira forma dois enunciados distintos ou apenas um?". Se a referência ao enunciado, na perspectiva foucaultiana, implica não meramente a materialidade linguística, mas a constituição de um elemento de saber que funciona no interior de um discurso, a própria pergunta do filósofo nos leva a crer que, modificadas as condições de produção e as formações discursivas envolvidas, um "enunciado traduzido" não produz necessariamente os mesmos efeitos de sentido. Inclusive uma mesma materialidade linguística, se repetida em uma única língua, mas a partir de campos de correlação diferentes, pode suscitar enunciados diversos.

HUTCHEON (2011: 9) defende que "a tradução inevitavelmente altera não apenas o sentido literal, mas também certas nuances, associações e o próprio significado cultural do material traduzido". Tal perspectiva não se restringe à noção de valor do signo linguístico, conforme apresentada por SAUSSURE (1972), embora tal noção seja fundamental para a apreensão do funcionamento dos signos. Além da oposição entre signos que se delimitam no interior dos sistemas linguísticos, é necessário destacar o funcionamento desses signos com relação a uma exterioridade constitutiva, o que implica fatores culturais, sociais e históricos.

SelLIGMANN-SILVA (2005: 169) descreve ainda que, "no relativismo cultural que se estabeleceu, sobretudo, a partir da segunda metade do século 
KHALIL, L. - A questão da tradução em versões brasileiras de canções anglófonas

XVIII, desenvolveu-se a consciência da impossibilidade da tradução de uma cultura ou discurso para outra cultura ou língua", impossibilidade que seria causada por motivos linguísticos, por motivos externos à língua e, inclusive, por determinada "intraduzibilidade de elementos estéticos" (SELLIGMANN-SILVA, 2005: 224). Por outro lado, há perspectivas que defendem a possibilidade de uma tradução universal, que abarcaria certa noção de "tradução do mundo" por meio da língua. "Para Friedrich Schlegel, deveria ser possível uma 'tradução do universo'” (SelLIGMAnN-SILVA, 2005: 171). Considerando que tal lógica representacionista (que relaciona a língua diretamente às "coisas do mundo") é passível de falhas inclusive em reformulações linguísticas no interior de uma mesma língua, o translinguismo só tende a amplificar os deslizamentos de sentido.

O que Foucault (2000) chama de "fielmente traduzido" e Hutcheon (2011) de "sentido literal" é geralmente perpassado pelas noções de tradução que se cristalizaram em certos domínios. Há muita concordância em relação ao fato de toda tradução engendrar uma adaptação, sobretudo em textos poéticos (e por que não em letras de música?), cuja sonoridade aponta para aspectos da própria construção semântica. Em um sentido lato de tradução, todo ato de adaptar seria também um ato de traduzir? Isto é, mesmo que sejam alteradas as temáticas ou o desenvolvimento narrativo, os textos declaradamente adaptados seriam também traduções? Sabemos que os caminhos que levam à paráfrase, à paródia, à retextualização, são bastante específicos e, por isso, a utilização desse sentido amplo de "tradução" tende a instaurar polêmicas e incompreensões com relação às diversas modalidades de adaptação que encontramos no mercado cultural. Para citarmos um exemplo, a paródia é um tipo de adaptação que, nos Estados Unidos, pode circular livremente por lei, enquanto as adaptações de livro para filme estão sempre sujeitas à negociação por direitos autorais:

As adaptações não são apenas produzidas pelo desejo capitalista de lucrar; elas também são controladas legalmente por esse mesmo desejo, pois constituem uma ameaça à propriedade cultural e intelectual. É por isso que os contratos buscam absolver as editoras e 
KHALIL, L. - A questão da tradução em versões brasileiras de canções anglófonas

os estúdios de quaisquer consequências legais de uma adaptação (HUTCHEON, 2011: 129).

Declarar um produto cultural como uma tradução ou como uma adaptação é uma prática que traz, em nossa sociedade, importantes consequências. Nota-se que a noção de tradução carrega, em diversos casos, um estigma de "fidelidade" um pouco mais marcado do que quando se fala em adaptação. As versões musicais que estudamos em nossa pesquisa concentram essa fidelidade, em geral, na estrutura melódica das cançõesbase. O conceito de adaptação desenvolvido por HUTCHEON (2011), apreendendo a adaptação como obra declaradamente "derivativa", poderia ser suficiente para abarcar o fenômeno. Porém, o que está em questão não é simplesmente afirmar ou negar o fato de as versões serem adaptações, mas discutir o que essa denominação reserva para o status dos produtos culturais como obras que "derivam" de outro lugar.

A adaptação, no sentido conferido por HUTCHEON (2011: 29), constitui-se como uma espécie de "transcodificação", aferida a partir de diversos caminhos:

Essa transcodificação pode envolver uma mudança de mídia (de um poema para um filme) ou gênero (de um épico para um romance), ou uma mudança de foco e, portanto, de contexto: recontar a mesma história de um ponto de vista diferente, por exemplo, pode criar uma interpretação visivelmente distinta.

No caso das versões nacionais de canções anglófonas, não é possível verificar uma mudança de mídia, isto é, não se transforma as canções-base em filmes ou contos, por exemplo, mas sim em outras canções. Sendo tais versões declaradamente produzidas a partir de outra canção, podemos dizer que há, em contrapartida, uma mudança de entornos, que, assim como a "mudança de foco" citada por HUTCHEON (2011), torna possíveis distintas interpretações. A adaptação não configura, portanto, uma simples repetição, mesmo que possamos eventualmente levantar a hipótese da paráfrase. A produção de uma obra considerada adaptada situa-se no entremeio de 
KHALIL, L. - A questão da tradução em versões brasileiras de canções anglófonas

elementos já dados e a tentativa artística da novidade: "Dado o grande número de adaptações em todas as mídias hoje em dia, vários artistas parecem ter escolhido assumir essa dupla responsabilidade: adaptar uma outra obra e torná-la uma criação autônoma" (HUTCHEON, 2011, p. 124). 0 fenômeno em estudo, desse modo, envolve mais o apelo comercial e a busca por novos públicos, a partir de um objeto supostamente autônomo, do que propriamente um tributo à canção-base. Partindo de melodias que ressoam no "arquivo auditivo" de um público extenso, as versões brasileiras de canções anglófonas abrem espaço a outras modalidades de circulação que se encerram em consideráveis ressignificações.

A letra de música e o poema compartilham algumas importantes características, como a estruturação em versos, o trabalho com a sonoridade e a recorrência de rimas. Tal constatação nos faz retornar ao dilema tradução/ adaptação. 0 tradutor de poemas, em geral, fica atento às singularidades semânticas dos elementos sonoros para recriar os versos em outra língua, prática que, muitas vezes, autoriza o tradutor a escapar da controversa "tradução literal" ou da tradução "palavra por palavra". Para citarmos um exemplo, a palavra "nevermore", que ressoa no poema $O$ corvo, de Edgar Allan Poe, quando traduzida para o português, fatalmente não provoca os mesmos efeitos de sentido, o que levou diversos tradutores de língua portuguesa, como Machado de Assis e Fernando Pessoa, a estabelecer outras estratégias que combinassem a sonoridade peculiar do português à carga semântica geralmente atribuída ao poema. Ao discorrer sobre a prática da tradução, JAKOBSON (1995: 72) afirma que, na poesia, "a semelhança fonológica é sentida como um parentesco semântico". Isso significa dizer que o trabalho com a sonoridade permite algumas mudanças substanciais de palavras e expressões sem que se negue o caráter de "tradução".

Selligmann-Silva (2005: 198) ressalta que, "para Haroldo de Campos, [...] os textos que possuem uma relação mais 'frouxa' com o sentido são justamente os que se prestam à verdadeira tradução". A poesia e a letra de música, pelo fato de tratarem os temas, na maioria das vezes, de uma 
KHALIL, L. - A questão da tradução em versões brasileiras de canções anglófonas

maneira circular, isto é, não obedecendo a uma narrativa linear, são submetidas à tradução de uma forma um pouco menos "presa" do que ocorreria com relação a um artigo científico, a uma notícia ou a um romance.

Os versos da canção I remember you, "Remember yesterday/ walking hand in hand", da banda Skid Row, por exemplo, foram adaptados, na versão brasileira produzida pela banda tecnobrega Mulheres Perdidas, como "Não vou te esquecer/ Não vou te perder", fato que claramente escapa à "tradução palavra por palavra". No entanto, os pares "lembrar-se de ontem" / "não esquecer" e "andar de mãos dadas" / "não perder" corroboram a interpretação de que há certa proximidade semântica no tratamento da temática amorosa: enquanto "lembrar" torna-se "não esquecer", "andar de mãos dadas”, de certa forma, é não "abrir mão" do ser amado, não perdê-lo. Essas consideráveis mudanças, em relação a uma suposta tradução literal, efetuam-se justamente a partir da primazia da semelhança fonológica alçada à semelhança semântica: a sílaba de maior tonicidade dos quatro versos coincide com a sílaba final, caracterizada pela vogal anterior fechada /e/, no português, e por um fonema próximo no inglês: esquecer, perder, yesterday, hand.

Do mesmo modo, "Sweet child o' mine", título de uma canção da banda Guns n' Roses, tornou-se "Te quero mais", verso que ressoa no refrão da versão produzida pela banda tecnobrega Brucelose. Embora "mine" e "mais" não sejam palavras consideradas "correspondentes" na relação entre inglês e português, privilegia-se novamente a sonoridade, mantendo a consoante bilabial nasal sucedida do ditongo decrescente. Mais do que um parentesco fonológico, essa semelhança ocasiona uma proximidade semântica no tratamento da temática amorosa.

Se investigássemos as diversas versões brasileiras de canções anglófonas à procura de fatos linguísticos análogos aos que acabamos de demonstrar, muitos outros exemplos poderiam ser apresentados e discutidos. De forma geral, a reflexão que desenvolvemos até aqui só acirra o impasse entre as utilizações dos termos "adaptação" e "tradução". Longe de querermos 
KHALIL, L. - A questão da tradução em versões brasileiras de canções anglófonas

universalizar e estabilizar o uso de palavras que poderiam abarcar o fenômeno em questão, o termo "versão" concede-nos a impressão de maior globalidade, pois, em dadas utilizações, permite conjuntar especificidades tanto atribuídas ao termo "adaptação" quanto ao termo "tradução". A oscilação entre o adaptar e o traduzir, por sua vez, demonstra ainda mais densamente a complexidade do comportamento dos enunciados frente às materialidades linguísticas que estão envolvidas em cada enunciação.

Além de termos como versão, tradução e adaptação, alguns outros também são empregados em enunciações sobre as versões brasileiras de canções anglófonas. É o caso da palavra "imitação", utilizada pelo historiador TINHORÃo (2010: 354) em referência à geração lê-lê-lê, de músicos brasileiros influenciados por bandas como The Beatles nas décadas de 1950 e 1960:

Em pouco tempo começaram a surgir as imitações nacionais, entre as quais algumas risíveis, como a do conjunto Os Cometas (réplica dos Comets de Bill Halley) aparecida em abril de 1957 sob o selo Odeon com os rocks "Não Pise no Sapato" e "Ski-Rock-Ski-Rock".

Nota-se que a escolha pelo termo "imitação" está intimamente ligada a um julgamento qualitativo depreciativo em relação às versões nacionais. Para o autor, elas são dignas de riso, configuram-se como "réplicas", seriam destituídas de "originalidade" e, portanto, desprezíveis.

Escolher entre adaptação ou tradução, entre versão e imitação, é uma prática que nos remete à pergunta que ressoa em grande parte da Arqueologia do saber, obra de FoucAult (2000): por que um enunciado e não outro em seu lugar? Defende-se que a utilização de um termo ou de outro coloca em cena formações discursivas diferentes e, consequentemente, redes conceituais que instauram determinada vizinhança entre os objetos nos campos discursivos da arte e da música. Enquanto, de algumas perspectivas, a tradução é concebida sob a norma da "fidelidade" ao texto-base, outras perspectivas atribuem certa convergência entre traduzir e adaptar ou entre traduzir e produzir uma versão. Diferentemente, o termo imitação, dadas as condições de produção das versões, é delineado, na maioria das vezes, por um 
teor pejorativo, pois coloca em questão noções como "originalidade" ou mesmo "detenção de direitos legais". O embate que envolve tais nomenclaturas, desse modo, é fundamental para o fenômeno que estudamos, na medida em que elas constituem parte da rede enunciativa que antecede e funciona como exterioridade às canções.

\section{Análise: Essa noite foi maravilhosa}

Para ampliarmos as reflexões arroladas no tópico anterior, focalizaremos a letra da canção Essa noite foi maravilhosa, de Leandro e Leonardo, versão de Wonderful Tonight, de Eric Clapton. Como já adiantado, a letra dessa versão aproxima-se, em alguns momentos, do que se costuma denominar "tradução literal", expressão que utilizamos com certas ressalvas anteriormente discutidas.

\section{Wonderful tonight}

Eric Clapton

It's late in the evening

She's wondering what clothes to wear.

She puts on her make-up and brushes her long blonde hair.

And then she asks me, "Do I look all right?"

And I say, "Yes, you look wonderful tonight"

We go to a party and everyone turns to see This beautiful lady that's walking around with me.

And then she asks me, "Do you feel all right?"

And I say, "Yes, I feel wonderful tonight."

I feel wonderful because I see

The love light in your eyes.

And the wonder of it all

Is that you just don't realize how much I

\section{Essa noite foi maravilhosa \\ Leandro e Leonardo}

A noite vem vindo

Estrelas brilhando em nós

Te vejo sorrindo e ouço a sua voz Me perguntando se eu te gosto assim

Digo que sim toda linda só pra mim

No meio da festa tentam flertar você

Mas você me abraça dizendo que só me vê

Parece um sonho vejo em seu olhar Tanta paixão tenho medo de acordar.

Esta noite eu sou o homem mais feliz que o amor já fez Meu silêncio quer dizer pra você 
KHALIL, L. - A questão da tradução em versões brasileiras de canções anglófonas

love you.

It's time to go home now and l've got an aching head,

So I give her the car keys and she helps me to bed.

And then I tell her, as I turn out the light, I say, "My darling, you were wonderful tonight.

Oh my darling, you were wonderful tonight. mais uma vez como eu te amo.

As luzes se apagam, a festa acabou Sobre o banco do carro fazemos amor

Maravilhosa seu sorriso me diz Mais uma noite em que a gente foi feliz.

Vale salientar que as canções contêm a mesma estrutura melódica, porém realizada em tons diferentes. Embora o arranjo da versão não sofra grandes alterações, notamos a ausência do órgão que acompanha a melodia da canção-base, preterido pelo teclado, e a presença de alguns pequenos solos adicionais de guitarra, utilizando efeitos de modulação característicos do estilo que se conhece como country. Tratando-se de uma dupla sertaneja, a chamada "segunda voz" é perceptível em algumas partes da versão, sobretudo nos refrãos. Por fim, a duração das canções é bastante aproximada, apenas um segundo de diferença. As modificações, embora sirvam de justificativa para deslocamentos estilísticos, não nos parecem apontar, sozinhas, para a mandatória presença do "estilo rock" em uma canção e do "estilo sertanejo" em outra.

Embora a letra da versão, em comparação com a letra da canção-base, contenha algumas semelhanças, sobretudo na sequenciação das ações, algumas diferenças precisam ser evidenciadas, considerando a problemática acerca das materialidades do enunciado, empreendida no tópico anterior.

Wonderful tonight e Essa noite foi maravilhosa são canções desenvolvidas a partir de uma estrutura que se aproxima consideravelmente da narrativa. Em ambas as canções, o enunciador narra em primeira pessoa a sua ida a uma festa na companhia de uma mulher, provavelmente sua esposa. $\mathrm{Na}$ canção anglófona, a hipótese do casamento é mais palpável, pelo aparente fato de o casal morar junto. A mulher inclusive questiona qual roupa usar ao companheiro antes de saírem de casa. A versão, por sua vez, não sugere 
KHALIL, L. - A questão da tradução em versões brasileiras de canções anglófonas

necessariamente esse tipo de união, tendo em vista que o casal "faz amor sobre o banco do carro" após a festa. De uma forma global, podemos dizer que as semelhanças das partes narrativas são mais evidentes nos momentos que precedem a festa e no decorrer da festa. As ações que sucedem a festa são mais divergentes, embora o desfecho da canção seja linguisticamente bastante parecido.

A análise dos tempos verbais ajuda a demonstrar a convergência entre as canções. Ambas iniciam-se com versos que indicam ações contínuas "She's wondering what clothes to wear" / "A noite vem vindo, estrelas brilhando em nós" -, construindo a ambientação anterior à festa. Nas segunda e terceira estrofes, há um predomínio do presente do indicativo, no português, e do simple present, no inglês - "We go to a party and everyone turns to see" / "No meio da festa tentam flertar você" -, em expressões relativas às ações que ocorrem no momento da festa. Por fim, a última estrofe de cada canção apresenta uma visão retrospectiva da noite vivenciada pelo casal, utilizando verbos no passado: "You were wonderful tonight" / "Mais uma noite em que a gente foi feliz".

A história narrada nas duas canções inicia-se com uma atmosfera de contemplação. Enquanto a mulher se apronta para a festa, o homem faz elogios à amada e a incentiva, quando perguntado se ela estaria realmente bonita. A principal diferença entre a primeira estrofe das duas canções consiste no fato de a canção-base referir-se diretamente à maquiagem e ao penteado para criar o pano de fundo elogioso, enquanto a versão estabelece uma conjunção entre o ser amado, por meio do sorriso e da voz, e fenômenos naturais, a vinda da noite e o brilho das estrelas, outro caminho possível para anteceder e constituir o elogio.

A expressão "I say yes", ainda na primeira estrofe, tornou-se "Digo que sim" na versão. Esse processo, supostamente uma "tradução literal", não age isoladamente, pois interfere em toda a estrutura rímica da música. Embora a canção anglófona apenas aponte a beleza da mulher em questão ("You look wonderful tonight"), a versão acrescenta a essa qualidade um sentimento de 
posse, de exclusividade ("Toda linda só pra mim"), justamente porque, no processo de produção da versão, pôde-se escolher a palavra "mim" por ressoar as vogais tônicas de "assim", do verso anterior, e "sim", do mesmo verso, diferente das rimas "right" e "tonight", em posições análogas na canção anglófona. Lembremos que, em poesia e em letra de música, muitas vezes a carga semântica subordina-se à sonoridade, atenuando esse tipo de diferença em adaptações e/ou traduções.

A segunda estrofe, em ambas as canções, estabelece um momento de tensão: devido à esplendorosa beleza da mulher, ela torna-se o centro das atenções da festa, o que instaura uma rápida instabilidade na relação do casal. Essa tensão é tratada de forma um pouco mais direta na versão brasileira, na qual "tentam flertar" a mulher. A canção anglófona, por sua vez, apenas retrata os convidados da festa olhando para a mulher com admiração, sem expressar explicitamente as intenções dessas pessoas que a observam. A situação incômoda resolve-se de forma muito mais direta, também, na canção em português: a mulher abraça o companheiro, dizendo não se importar com os flertes. 0 circunlóquio da canção-base consiste no ato de a mulher perguntar se o companheiro sente-se bem e ele responder que sim, aliviando a tensão. A utilização da palavra "wonderful" ("I feel wonderful tonight") no verso em questão evidencia um jogo de sentidos entre o exterior e o interior: enquanto "I feel wonderful tonight", da segunda estrofe, aponta para um estado sentimental do enunciador, o verso "You look wonderful tonight", da primeira estrofe, aponta para um estado físico, a beleza da mulher.

A terceira estrofe, ou refrão, da versão inicia-se com uma sentença "Essa noite eu sou o homem mais feliz que o amor já fez" - que pode indiciar, ao crítico musical interessado em avaliar a qualidade da canção, a presença do exagero sentimental, suposta característica da música brega. A cançãobase, por sua vez, expressa na mesma posição os versos "I feel wonderful because I see the love light in your eyes". Embora suscitem sentimentos de felicidade relativos a uma semelhante confirmação amorosa, o 
KHALIL, L. - A questão da tradução em versões brasileiras de canções anglófonas

questionamento que nos resta com relação a esses versos é: enxergar a "luz do amor" ou o "amor brilhar" nos olhos da amada é uma expressão tão exagerada quanto "ser o homem mais feliz do mundo"? Sugere-se, com essa comparação, que a constituição de um status brega é fundamentalmente legitimada por aquilo que é imposto pela exterioridade, e não por uma configuração estritamente interna da letra da canção.

O término da terceira estrofe das duas canções, a partir de construções linguísticas diferentes, também parece corroborar a hipotética tentativa da versão em buscar constantemente amparo na canção-base. Enquanto, na canção de Eric Clapton, os versos "You just don't realize how much I love you" exprimem a impossibilidade de a companheira apreender tão grande amor, a canção de Leandro e Leonardo explora essa inefabilidade a partir da inclusão de um silêncio significante: "Meu silêncio quer dizer pra você mais uma vez como eu te amo". O inapreensível e o inefável entram em uma conjunção possibilitada pelo próprio teor romântico das canções, ambas apresentando uma perspectiva positiva da relação amorosa vivenciada.

Conforme adiantamos, a última estrofe das canções constitui o ponto de maior divergência. 0 início e o fim da estrofe são, em contrapartida, bastante próximos. Essa proximidade consiste, quanto ao verso final, na apresentação de uma visão retrospectiva. 0 verso inicial assemelha-se por exercer a função de indicar o fim da festa; porém, isso ocorre a partir de estratégias diferentes: enquanto "It's time to go home now" pressupõe implicitamente o fim da festa, "As luzes se apagam, a festa acabou", apesar de apresentar inicialmente um índice - o apagar das luzes -, encerra-se com a indicação explícita do fato narrado.

É depois de acabada a festa que as histórias narradas recebem um rumo um pouco diferente. 0 desfecho da canção-base cria uma atmosfera de ternura, relatando a ida do casal, ao final da noite, para a cama. A mulher, inclusive, dirige o carro, provavelmente de seu companheiro ("I give her the car keys"), e o ajuda a deitar-se, pelo fato de ele estar com dor de cabeça após a festa. A versão nacional, por sua vez, tem seu desfecho ainda no carro, 
KHALIL, L. - A questão da tradução em versões brasileiras de canções anglófonas

com uma referência à prática sexual, que constitui uma espécie de auge da noite de plena felicidade do casal. "Fazemos amor" não se configura exatamente como sinônimo de "amamos", por exemplo, expressão que pode ou não suscitar o ato sexual. Ademais, a sequência "sobre o banco do carro" indicia que há um panorama propriamente físico envolvido na ação descrita. É justamente após o verso "Sobre o banco do carro fazemos amor" que há a única menção à palavra "maravilhosa", presente no título da versão.

O desenrolar das histórias é diferente, mas não contraditório, pois a perspectiva sobre o amor continua sendo de contemplação e satisfação. Por outro lado, a ênfase concedida ao sexo produz efeitos de sentido peculiares. Tal referência pode ser considerada como uma "vulgarização do amor"? E o mais importante: essa vulgarização seria o diferencial para que se atribua o status brega a Leandro e Leonardo e não a Eric Clapton? VITAL (2012), por exemplo, relaciona a palavra "brega" a "show de sensualidade extrema e música vulgarizada", em artigo do campo da Sociologia. Entendemos que suposições como essa apenas agem no sentido de estabilizar e justificar as classificações musicais, rede de conceitos que adquirem sentido a partir de dada exterioridade constitutiva. As descontinuidades desse tipo de associação, no entanto, são evidenciadas a partir da investigação de outros gêneros musicais, como o próprio rock, haja vista a famosa expressão Sex, drugs and rock ' $n$ ' roll.

Apesar de a letra da versão possibilitar algumas estratégias de argumentação para discursos que associem artistas como Leandro e Leonardo ao status brega, pode-se notar, com uma análise que investiga as singularidades dos sentidos e não as universalizações, o primado da exterioridade sobre uma "essência" interna das canções. 0 ato de focalizar estritamente as letras resulta, sim, em distanciamentos, mas também em aproximações, fato que não atesta fatalmente um transpasse de estilos musicais, embora nosso objetivo não seja definir de modo universal as fronteiras entre esses estilos. 
Com relação à tensão entre tradução e adaptação, problemática focalizada neste recorte, o aspecto que melhor define a não interpretação da versão como "tradução", longe de ser determinado por um "nível de fidelidade", é o funcionamento da canção frente ao público, principalmente a partir das práticas empreendidas em sua circulação e em sua recepção. Em outras palavras, o público que ouve Essa noite foi maravilhosa não a ouve como uma espécie de "substituição à obra original", nem como um modo de suplantar uma hipotética inacessibilidade linguística em relação à canção Wonderful Tonight. O funcionamento das versões no âmbito musical é bastante peculiar, pois a manutenção de estruturas melódicas e a mudança de idiomas não apontam, isoladas de todo um complexo discursivo, para uma simples definição dos sentidos decorrentes desse novo objeto. 


\section{Referências bibliográficas}

ARrojo, Rosemary. Oficina de tradução: a teoria na prática. 4. ed. São Paulo: Ática, 2003.

Foucault, Michel. A Arqueologia do saber. Tradução Luiz Felipe Baeta Neves. 6. ed. Rio de Janeiro: Forense Universitária, 2000 [1969].

HUTCHEON, Linda. Uma teoria da adaptação. Tradução de André Cechinel. Florianópolis: Editora da UFSC, 2011.

JAKOBSON, Roman. Aspectos linguísticos da tradução. In: Linguística e comunicação. São Paulo: Cultrix, 1995: 63-72 [1969].

SAUSSURE, Ferdinand de. Curso de linguística geral. Organizado por Charles Bally e Albert Sechehaye. 4. ed. São Paulo: Cultrix, 1972 [1916].

Selligmann-Silva, Márcio. O local da diferença: ensaios sobre memória, arte, literatura e tradução. São Paulo: Editora 34, 2005.

VITAL, Cleyton Douglas. Brega, kitsch, mau gosto: a TV e a música vulgarizada. Disponível em: <http://www.observatoriodaimprensa.com.br/brega_ kitsch_mau_gosto_a_tv_e_a_musica_vulgarizada>. (08/09/2012). 